\title{
Hubungan Tingkat Pendidikan dengan Spiritual Well Being Warga Binaan Pemasyarakatan Laki-laki di Lembaga Pemasyarakatan Jawa Tengah
}

\author{
Dwi Fijianto', Nurul Aktifah², Herni Rejeki ${ }^{3}$
}

1. Fakultas Ilmu Kesehatan Universitas Muhammadiyah Pekajangan Pekalongan, email:

$$
\text { viaradwi@gmail.com }
$$

2. Fakultas Ilmu Kesehatan Universitas Muhammadiyah Pekajangan Pekalongan

3. Fakultas Ilmu Kesehatan Universitas Muhammadiyah Pekajangan Pekalongan

\begin{abstract}
Abstrak. Peningkatan Warga Binaan Pemasyarakatan (WBP) di Dunia terjadi setiap tahun. Data World Prison Population List tahun 2014 menunjukkan Indonesia menempati urutan sepuluh besar jumlah Warga binaan Pemasyarakan terbanyak. Sebagian besar Lembaga Pemasyarakatan Laki-laki mengalami kelebihan daya tampung WBP, sehingga menjadi penyebab masalah psikososial yang akan berdampak terhadap spiritual well being WBP laki-laki. Tingkat pendidikan WBP dapat mempengaruhi spiritual well being WBP. Tingkat pendidikan sangat bervariasi sehingga tingkat spiritual well being berbeda antar WBP. Tujuan penelitian untuk mengetahui hubungan antara tingkat pendidikan dengan tingkat spiritual well being WBP laki-laki. Jenis penelitian adalah kuantitatif dengan metode penelitian cross sectional. Pengambilan sampel menggunakan non probability sampling dengan metode purposive sampling. Analisis univariat dilakukan untuk mengetahui karakteristik responden WBP laki-laki. Analisis bivariat menggunakan uji Spearman rho untuk mengetahui hubungan tingkat pendidikan dengan tingkat spiritual well being WBP laki-laki. Jumlah sampel 105 responden yang sesuai dengan kriteria inklusi yaitu WBP laki-laki yang bisa membaca, WBP laki-laki yang kooperatif, dan WBP laki-laki yang berusia $>17$ Tahun. Pengambilan data menggunakan instrument Spiritual Well Being Scale (SWBS) Ellison. Hasil penelitian menunjukkan ada hubungan yang signifikan antara tingkat pendidikan dengan spiritual well being WBP laki-laki dengan nilai $p$ 0,000. Hubungan antar variabel adalah hubungan positif, semakin tinggi tingkat pendidikan maka akan semakin tinggi tingkat spiritual well being. Simpulan penelitian ini adalah ada hubungan yang signifikan antara tingkat pendidikan dengan spiritual well being WBP laki-laki.
\end{abstract}

Kata kunci: tingkat pendidikan, spiritual well being, WBP laki-laki.

\section{Correlation Between the Level of Education with Spiritual Well Being of Male Inmates at the Correctional Institution in Central Java}

Abstract. The increase of male inmates in the World occurs every year. World Prison Population List data for 2014 shows Indonesia ranks in the top ten in the number of inmates. Most male correctional institutions experience excess capacity of male inmates, so that it causes psychosocial problems that will have an impact on the spiritual well being of male inmates. The level of inmates education can affect the spiritual well being of inmates. The level of education varies greatly so that the level of spiritual well being differs between. The purpose of this study was to determine the relationship between the level of education with the level of spiritual well being male inmates. This type of research is quantitative with cross sectional research methods. Sampling uses non probability sampling with a purposive sampling method. Univariate analysis was performed to determine the characteristics of male inmates respondents. Bivariate analysis uses the Spearman rho test to determine the relationship of education level with the level of spiritual well being of male inmates. Total sample of 105 respondents who fit the inclusion criteria were male inmates who could read, male inmates who were cooperative, and male inmates who are more than 17 years old. Retrieval of data using Ellison's Spiritual Well Being Scale (SWBS) instrument. The results showed there was a relationship between the level of education with the spiritual well being of male inmates with a p value 0.000. The relationship between variables was a positive relationship, the higher the level of education the higher the level of spiritual well being. The conclusion of this research there is a significant relationship between the level of education and spiritual well being of male inmates.

Keywords: education level, spiritual well being, male inmates. 


\section{Pendahuluan}

Peningkatan jumlah Warga Binaan Pemasyarakatan (WBP) di dunia terjadi setiap tahun. Data World Prison Population List tahun 2014 menunjukkan Indonesia menempati urutan sepuluh besar jumlah WBP di dunia. Jumlah WBP pada tahun tersebut sebanyak 161.692 WBP di Indonesia.

Data WBP Direktorat Jenderal Pemasyarakatan (Ditjenpas) pada Sistem Database Pemasyarakatan tahun 2020 menunjukkan bahwa di Indonesia terjadi peningkatan jumlah WBP laki-laki setiap tahun. Data Januari 2020 WBP laki-laki di Indonesia berjumlah 190.517 orang. Urutan WBP terbanyak terdapat pada Kantor Wilayah (Kanwil) Sumatera Utara, Jawa Timur, Jawa Barat, dan Jawa Tengah. Sebagian besar Lembaga Pemasyarakatan (Lapas) melebihi daya tampung.

Astuti (2011) menjelaskan masalah psikososial terjadi pada WBP karena lapas yang melebihi daya tampung. Masalah psikososial WBP laki-laki yang dialami sangat kompleks seperti merasa dirinya tidak berguna, putus asa, sedih, dan kecewa sehingga berpengaruh terhadap spiritual well-being WBP laki-laki (Hatala, 2013 \& Gallagher, 2001).

Kesejahteraan spiritual (Spiritual wellbeing) merupakan sebuah konsep tentang bawaan, yang bersifat dinamis dan subjektif pada suatu hal yang diyakini sebagai sebuah kebenaran untuk memotivasi dan mendorong manusia untuk mencapai tujuan hidup. (Gomez \& Fisher, 2005 dan Eksi \& Kardas, 2017).

\section{Paloutzian}

dkk

(2009)

mengungkapkan beberapa hal yang mempengaruhi tingkat Spiritual well-being WBP laki-laki. Pengalaman hidup atau pembelajaran WBP selama hidupnya dapat mempengaruhi tingkat Spiritual well-being . pembelajaran WBP laki-laki dalam meyakini, mempersepsikan dan berhubungan dengan Tuhan. Pengalaman yang menyenangkan maupun menyedihkan dapat memengaruhi keyakinan WBP lakilaki terhadap Tuhan. Pengalaman hidup
WBP menjadi acuan dalam berhubungan dengan Tuhan dan berhubungan dengan sesame (Ellison 1983, Fisher 2009, Azizah 2011, dan Bini'matillah 2018).

Pengalaman dan pembelajaran seorang WBP dapat ditemukan diantaranya melalui proses pendidikan (Sadullah, 2014) Tingkat pendidikan WBP sangat bervariasi, sehingga pengalaman dan pembelajaran terhadap Spiritual well-being juga bervariasi.

Penelitian ini dilakukan untuk mengetahui hubungan antara tingkat pendidikan dengan tingkat Spiritual wellbeing WBP laki-laki. Andriany 2011 dan ambarkati 2018 mengungkapkan Perawat correctional berperan dalam membina pendidikan dan kesejahteraan spiritual WBP, sehingga penting diketahui adakah hubungan tingkat pendidikan dengan Spiritual well-being WBP laki-laki.

\section{Metode}

Penelitian ini menggunakan desain penelitian croos sectional. Penelitian dengan melakukan pengukuran atau pengamatan pada saat bersamaan atau observasi data variabel independen dan dependen dalam satu kali pada saat itu (Nursalam, 2017). Populasi responden penelitian adalah WBP laki-laki di Lapas Kelas I A Semarang dan Lapas Kelas II B Brebes. Pelaksanaan penelitian dilakukan pada bulan Maret 2020.

Pengambilan sampel dalam penelitian menggunakan teknik non probability sampling dengan metode purposive sampling. Metode purposive sampling merupakan penentuan sampel dengan pertimbangan tertentu. Alasan pemilihan sampel menggunakan metode ini karena tidak semua sampel memiliki kriteria yang sesuai dengan yang penulis tentukan (Sugiyono, 2017).

Jumlah sampel dalam penelitian adalah 105 responden. Sampel diambil sesuai dengan kriteria inklusi (Sugiyono, 2017). Kriteria inklusi sampel penelitian yaitu WBP laki-laki yang bisa membaca, 
WBP laki-laki yang kooperatif, dan WBP laki-laki yang berusia $>17$ Tahun.

Instrumen yang digunakan dalam pengambilan sampel penelitian adalah kuesioner karakteristik responden dan kuesioner spiritual well being scale (SWBS). Pengisian kuesioner dilakukan oleh responden setelah mengisi form persetujuan responden/ informed concent. SWBS adalah alat ukur untuk mengetahui tingkat spiritual well being. Kuesioner yang peneliti gunakan adalah kuesioner SWBS. Kuesioner SWBS adalah kuesioner yang valid dan telah digunakan oleh peneliti sebelkumnya. Uji validitas dan realibilitas kuesioner SWBS sudah dilakukan dengan nilai validitas cronbach alpha $>0,8$ dan nilai reliabilitas cronbach alpha $=0,895$ (Utama, 2015).

Kuesioner Spiritual well-being Scale (SWBS) dibuat dan dikembangkan oleh Palutzian and Ellison yang terdiri dari 20 item pertanyaan. Pertanyaan terbagi ke dalam dua dimensi spiritual well-being, yaitu 10 item pertanyaan menunjukkan dimensi religiusitas (religious well-being), dan 10 item pertanyaan yang lain menunjukkan dimensi eksistensial (existential well-being). Setiap pertanyaan memiliki nilai minimal 1 dan nilai maksimal 6 (Ellison 1983 dan Paloutzian 2012).

Penilaian kuesioner SWBS dibagi menjadi tiga tingkatan yaitu spiritual wellbeing rendah dengan skor (20-40), spiritual well-being sedang dengan skor (41-99) dan spiritual well-being tinggi dengan skor (100120) (Ellison 1983 dan Paloutzian 2012).

Hasil pengambilan sampel selanjutnya dilakukan analisis data. Analisis data penelitian ini adalah analisis univariat dan analisis bivariat. Analisis univariat dilakukan untuk mendapatkan gambaran deskriptif tingkat pendidikan responden dan tingkat spiritual well being WBP laki-laki. Analisis bivariat dilakukan menggunakan uji spearman rho. $\mathrm{Uji}$ spearman rho dilakukan untuk mengetahui korelasi/hubungan antara dua variabel (Polit \& Beck, 2012).

\section{Hasil Penelitian}

Hasil penelitian didapatkan data karakteristik responden berupa data tingkat pendidikan dan data analisis univariat spiritual well-being WBP laki-laki. Hasil penelitian juga didapatkan hasil analisis bivariat yaitu hubungan antara tingkat pendidikan dengan spiritual well-being. Hasil penelitian disajikan pada tabel sebagai berikut:

\section{Karakteristik Responden}

a. Distribusi Tingkat Pendidikan Responden.

Tabel 1.1 Distribusi tingkat pendidikan responden $(\mathrm{N}=105)$

\begin{tabular}{cclcc}
\hline No & $\begin{array}{c}\text { Karakteristik } \\
\text { Responden }\end{array}$ & Kategori Tingkat Pendidikan & Jumlah & $(\%)$ \\
\hline 1 & $\begin{array}{c}\text { Tingkat } \\
\text { Pendidikan }\end{array}$ & Tidak Tamat SD & 14 & $13,3 \%$ \\
\cline { 2 - 4 } & SD & 13 & $12,4 \%$ \\
\cline { 2 - 4 } & SMP & 30 & $28,6 \%$ \\
\cline { 2 - 4 } & SMA & 39 & $37,1 \%$ \\
\cline { 2 - 4 } & Perguruan Tinggi & $9,6 \%$ \\
\hline \multirow{4}{*}{ Jumlah Total } & 105 & $100 \%$
\end{tabular}

Tabel di atas menunjukkan sebagian besar tingkat pendidikan responden adalah SMA sebanyak $37,1 \%$. Selanjutnya tingkat pendidikan SMP sebanyak 28,6\%, Tidak tamat SD $13,3 \%$, SD 12,4\%, dan tingkat pendidikan perguruan tinggi $8,6 \%$. Tingkat pendidikan lulusan perguruan tinggi paling sedikit di antara tingkat pendidikan WBP laki-laki.

\section{Analisis Univariat}

a. Analisis univariat tingkat pendidikan

WBP laki-laki dan spiritual well-being Tabel 2.1 Hasil analisis univariat tingkat pendidikan dan Spiritual Well- Being.

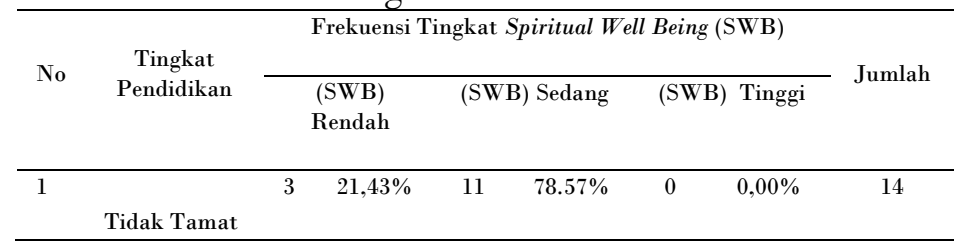




\begin{tabular}{lllllllll}
\hline \multicolumn{1}{c}{ SD } & & & & & & & \\
\hline 2 & SD & 1 & $7,69 \%$ & 12 & $92,31 \%$ & 0 & $0,00 \%$ & 13 \\
\hline 3 & SMP & 0 & $0,00 \%$ & 26 & $86,67 \%$ & 4 & $13,33 \%$ & 30 \\
\hline 4 & SMA & 0 & $0,00 \%$ & 26 & $66,67 \%$ & 13 & $33,33 \%$ & 39 \\
\hline 5 & $\begin{array}{l}\text { Perguruan } \\
\text { Tinggi }\end{array}$ & 0 & $0,00 \%$ & 5 & $55,56 \%$ & 4 & $44,44 \%$ & 9 \\
\hline & Jumlah Total & 4 & $3,81 \%$ & 80 & $76,19 \%$ & 21 & $20,0 \%$ & 105 \\
\hline
\end{tabular}

Tabel 2.1 menunjukkan sebagian besar WBP laki-laki memiliki tingkat spiritual well-being sedang sebanyak $76,19 \%$. Tingkat spiritual well being WBP laki-laki berdasarkan tingkat pendidikan menunjukkan presentase spiritual well-being tinggi terbesar pada tingkat pendidikan perguruan tinggi sebanyak 44,44\%, selanjutnya tingkat pendidikan SMA sebanyak $33,33 \%$. Sedangkan spiritual wellbeing sedang terbesar pada tingkat pendidikan SD sebanyak 92,31\%, selanjutnya tingkat pendidikan SMP sebanyak $86,67 \%$.

3. Analisis Bivariat

b. Analisis bivariat tingkat pendidikan WBP laki-laki dan spiritual well-being

Tabel 3.1 Hasil analisis bivariat tingkat pendidikan dan Spiritual Well- Being dengan menggunakan uji Spearman's rho.

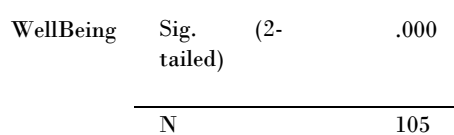

105

**. Correlation is significant at the 0.01 level (2-tailed).

Hasil analisis menunjukkan nilai koefisien korelasi sebesar 0,443 dan nilai $p$ value $0,000<0,05$ atau $(p<\alpha)$ yang berarti ada hubungan yang signifikan antara tingkat pendidikan dengan spiritual wellbeing WBP laki-laki. Hubungan antar variabel merupakan hubungan positif, artinya semakin tinggi tingkat pendidikan maka akan semakin tinggi tingkat spiritual well-being WBP laki-laki.

\section{Pembahasan}

Hasil penelitian didapatkan ada hubungan yang signifikan antara tingkat pendidikan dengan spiritual well-being WBP laki-laki. semakin tinggi tingkat pendidikan maka akan semakin tinggi tingkat spiritual well-being WBP laki-laki. Hasil penelitian ini sejalan dengan penelitian Laflamme (2004) yang menjelaskan bahwa pendidikan yang lebih tinggi akan mengajarkan orang untuk berpikir lebih logis dan rasional, dapat melihat kehidupan dari berbagai sisi sehingga dapat lebih melakukan analisis dan memecahkan suatu masalah kehhidupan. Pendidikan yang tinggi memperbaiki keterampilan kognitif yang diperlukan untuk dapat terus belajar di luar sekolah dalam mencapai suatu tujuan.

Fisher (2009) menjelaskan bahwa spiritual well being diantaranya dipengaruhi oleh pengalaman hidup dan pembelajaran. Semakin banyak pengalaman dan pembelajaran mengenai Tuhan dan

\begin{tabular}{llllll}
\hline & & & $\begin{array}{l}\text { Tingkat Pendidikan } \\
\text { Responden }\end{array}$ & $\begin{array}{l}\text { Tingkat Spiritua } \\
\text { WellBeing }\end{array}$ \\
\hline $\begin{array}{l}\text { Spearman's } \\
\text { rho }\end{array}$ & $\begin{array}{l}\text { Tingkat } \\
\text { Pendidikan } \\
\text { Responden }\end{array}$ & $\begin{array}{l}\text { Correlation } \\
\text { Coefficient }\end{array}$ & 1.000 & $.443^{* * *}$ \\
\cline { 3 - 6 } & $\begin{array}{l}\text { Sig. } \\
\text { tailed) }\end{array}$ & $(2-$ &. & .000 \\
\cline { 3 - 5 } & $\mathrm{N}$ & & 105 & 105 \\
\hline
\end{tabular}
kehidupan akan mempengaruhi persepsi dan pandangan terhadap Tuhan dan akan berpengaruh pada tujuan hidup manusia.

Ross dan Mirowsky mengemukakan bahwa akan berdampak positif dari lamanya (tahun) menempuh pendidikan dengan kesehatan yang konsisten, yang dapat diartikan bahwa lamanya tahun sekolah dapat mengembangkan kapasitas kehidupan yang 
efektif dengan tujuan akan mempengaruhi kesehatan baik fisik, mental maupun spiritual sehingga meningkatkan kesejahteraan, ekonomi, dapat mengontrol diri, lebih dapat mendukung sosial, dan bergaya hidup sehat.

Penelitian menunjukkan tingkat spiritual well-being WBP laki-laki yang tinggi sebagian besar terdapat pada WBP yang memiliki tingkat pendidikan yang lebih tinggi. Sewell WH (1975) menjelaskan Sekolah memberikan keterampilan umum, terutama berkaitan dengan kognitif, keterampilan khusus yang digunakan dalam meningkatkan kualitas dalam bekerja, nilainilai sosial, perilaku, spiritual dan mempunyai peran penting untuk pencapaian suatu tujuan hidup.

Tingkat pendidikan dan Spiritual wellbeing WBP laki-laki berpengaruh langsung terhadap kesehatan WBP laki-laki, baik kesehatan fisik, psikososial, dan spiritual. Fred (2010) mengungkapkan bahwa kurangnya pengetahuan dan akses informasi dapat menyebabkan seseorang memiliki keterbatasan pengetahuan terhadap bahaya perilaku tidak sehat dan menyebabkan kurang motivasi untuk menerapkan perilaku sehat. Hasil penelitian juga didukung penelitian Aini dkk (2018) yang mengungkapkan semakin tinggi tingkat pendidikan maka tingkat kesejahteraan kehidupan akanm semakin tinggi.

Penelitian ini mempunyai kelemahan dalam pelaksanaan dan hasil penelitian. Penelitian dilakukan dalam satu kali waktu pengambilan data, sehingga tidak dapat mengukur perubahan tingkat spiritual wellbeing WBP laki-laki secara periodic setelah mendapatkan informasi mengenai spiritual well-being.

\section{Simpulan}

Penelitian didapatkan ada hubungan yang signifikan antara tingkat pendidikan dengan spiritual well-being WBP laki-laki. Hubungan antar variabel merupkan hubungan positif, semakin tinggi tingkat pendidikan maka akan semakin tinggi tingkat spiritual well-being.

Saran peneliti: perawat komunitas dan atau correctional nursing dapat memberikan asuhan keperawatan spiritual bagi WBP laki-laki untuk meningkatkan spiritual well being WBP laki-laki, dengan demikian diharapkan WBP laki-laki dapat menyelesaikan masalah psikososial yang di alami di Lembaga Pemasyarakatan.

\section{Ucapan Terima Kasih}

Terima kasih penulis ucapkan kepada Universitas Muhammadiyah Pekajangan Pekalongan yang sudah memberikan kesempatan dan dukungan kepada penulis dalam menyelesaikan penelitian, serta pihak-pihak yang telah banyak membantu penulis dalam penyelesaian penelitian.

\section{Daftar Pustaka}

Aini EN, Isnaini I, Sukamti S. Pengaruh tingkat pendidikan terhadap tingkat kesejahteraan masyarakat di Kelurahan Kesatrian Kota Malang. Technomedia Journal; 2018; Vol.3 no.1.

Ambarkati T. Spiritual well being para narapidana perempuan muslim dalam pembinaan keagamaan di Lembaga Pemasyarakatan perempuan kelas II B Yogyakarta. J UIN Sunan Kalijaga. 2018.

Andriany M. Rencana narapidana wanita menghadapi kebebasan di lapas wanita kelas II a Semarang: konteks correctional nursing. Idea Nurs J.2011;3(Ii):1-10.

Astuti A. Pembinaan mental narapidana di Lembaga Pemasyarakatan Wirogunan Yogyakarta. J Citizsh.2011;1(1):29-45.

Azizah LM. (2010) Keperawatan lanjut usia. Yogyakarta: Graha Ilmu Bandiyah.

Bini'matillah U. Hubungan spiritualitas dengan kesepian pada lansia di UPT Pelayanan Sosial Tresna Werdha (PSTW) Jember. Digit Repos Univ Jember 2018;

Direktorat Pembinaan dan latihan Kerja Narapidana. Sistem database pemasyarakatan, kanwil \& ditjenpas. 2020 . 
Ellison CW. Spiritual well being: Conceptualization and measurement. J Psychol Theol 1983;11(4):330-8.

Fisher JW. Reaching the heart: assesing and nurturing spiritual well being. Disertation. Aust Univ Drive, Mt Helen Ballarat 2009.

Fred C. Pampel, Patrick M. Krueger, and Justin T. Denney. Socioeconomic Disparities in Health Behaviors. Annu Rev Sociol. August; 2010.36: 349-370.

Gallagher EM. Elders in prison health and wellbeing of older inmates. Law Psychiatry. 2001;24:325-33.

Gomez R, Fisher JW. Item response theory analysis of the spiritual well-being questionnaire. Personal Individ Differ 2005;38:1107-21.

Gurwood AS, Kabat AG. World prison population list, eleventh edition. 2014; (November 2014):1-15.

Hatala AR. Towards a biopsychosocial spiritual approach in health psychology : Exploring theoretical orientations and future directions. J Spiritual Ment Heal. 2013;(October):37-41.

Laflamme L, K. Engström, J. Möller, J. Hallquist. Is perceived failure in schools performance a trigger of physical injury? A case-crossover study of children in Stockholm County. Journal of Epidemiology and Community Health. 2004. no. 58, pp. 407-411.

Nursalam (2017) Metodologi Penelitian Ilmu Keperawatan: Pendekatan Praktis. (P. P. Lestari, Ed.) (4th ed.). Jakarta: Salemba Medika.

Paloutzian RF, Bufford RK, Wildman AJ. Spiritual well-being scale: mental and physical health relationships. Oxford Textb Spiritual Healthe 2012;353-8.

Polit, D.F and C.T Beck. (2012) Nursing Research; Generating and Assessing Evidences for Nursing Practices. 9th Ed. Lippincott Williams and Wilkin, China.

Ross CE. J. Mirowsky. Refining the association between education and health: the effects of quantity, credentials, and selectivity.
Demography.1999. vol. 36, no. 4, pp. $445-460$.

Sadulloh (2014) PEDAGOGIK (Ilmu Mendidik). Bandung: Alfabeta, cv.

Sewell W H. and Hauser RM. (1975) Education, Occupation and Earnings. Academic Press. p. 244. New York.

Sugiyono (2017) Metode Penelitian Kuantitatif, Kualitatif, dan R\&D. Bandung : Alfabeta, CV.

Utama TA. Perbedaan kesejahteraan spiritual pasien sebelum dan sesudah operasi jantung di RSUP Dr Hasan Sadikin Bandung. J Keperawatan Unpad 2015. 